\section{Fertility after treatment for cervical intraepithelial neoplasia}

SIR,-Messrs R H Hammond and D K Edmonds point out that cervical stenosis of such a degree to prevent the passage of sperm is rare.' Perhaps a more important problem resulting from surgery is distortion of the endocervical canal sufficient to hinder the transfer of embryos after in vitro fertilisation or of sperms during intrauterine insemination.

We treated a woman with primary infertility associated with mild endometriosis who had previously had laser vaporisation treatment for cervical intraepithelial neoplasia. On inspection her cervix appeared normal. She ovulated before oocyte retrieval in her first treatment cycle and intrauterine insemination was attempted instead. We could not cannulate her cervix with flexible or rigid transfer catheters. She subsequently chose gamete intrafallopian tube transfer in preference to in vitro fertilisation to avoid the possibility of failed embryo transfer.

Given the associations between previous chlamydial infection and premalignant disease of the cervix ${ }^{2}$ and tubal damage, ${ }^{3}$ the proportion of women with cervical intraepithelial neoplasia who have tubal infertility will probably be increased. The implications of this are twofold. Firstly, women about to undergo ablative treatment for premalignant disease of the cervix are more likely to have tubal infertility and, therefore, to require in vitro fertilisation and embryo transfer in the future. It could be argued that patients should be routinely advised of that association to avert litigation. Secondly, women being considered for an assisted conception programme who have had cervical surgery should undergo a mock embryo transfer before their treatment cycle. Any appreciable difficulty encountered should alert the doctor to the need for laser dilatation of the cervical $\mathrm{canal}^{4}$ or a change to one of the related techniques such as gamete intrafallopian tube transfer or zygote intrafallopian tube transfer.

ROBERT FOX DAVID J CAHILL

Bristol Maternity Hospital, Bristol BS2 8EG

1 Hammond RH, Edmonds DK. Does treatment for cervical intraepithelial neoplasia affect fertility and pregnancy? $B M \mathcal{F}$ 1990;301:1344-5. (15 December.)

2 Paavonen J, Vesterinen E, Mayer B, et al. Genital Chlamydia trachomatis infections in patients with cervical atypia. Obstet Gynecol 1979;54:289-95.

3 Conway D, Glazener CMA, Caul OE, et al. Chlamydial serology in fertile and infertile women. Lancet 1984; $1: 191-3$.

4 Luesley DM. Management of post-conisation stenosis by laser vaporisation. In: Sharp F, Jordan JA, eds. Gynaecological laser surgery. New York: Perinatology Press, 1985:97-105.

\section{Male rape}

SIR, - We agree with Dr Michael B King that male rape is underrecognised and underreported.' The social and psychological tensions experienced by victims of male rape have many parallels with those experienced by female victims 10 to 15 years ago.

The United States took the lead in the aftercare of rape victims with the development of specialised centres and teams to provide counselling and offer screening for sexually transmitted diseases. ${ }^{2}$ In the United Kingdom St Mary's sexual assault referral centre in Manchester is the only unit that offers a comprehensive forensic, counselling, and medical aftercare service to both male and female victims of sexual assault. In a review of characteristics of sexual assault in patients attending the centre $1 \%$ of referrals were men who had been assaulted by other men, often known to the victim. Their assault characteristics showed a striking similarity to those of female victims, with over half having symptoms suggesting the rape trauma syndrome.

Dr King expresses the need to screen male victims for HIV antibodies in view of the anal trauma that occurs in this form of assault. We found that less than a third of the male victims expressed anxiety about HIV infection, and, after counselling, only half of that third proceeded with testing. Anal intercourse is not limited to male rape but commonly accompanies female vaginal rape. We found that forced anal intercourse occurred in $19 \%$ of victims of female rape, and in $73 \%$ of cases some form of traumatic injury had occurred. ${ }^{3}$ Although we would not advocate automatic testing for HIV antibodies in all cases of rape, we believe that testing should be offered to all victims, regardless of sex, at an appropriate time after the assault.

Dr King pays scant regard to the need for victims to be screened for sexually transmitted diseases. Gonococcal and chlamydial infections are more likely to be acquired as a result of sexual assault than is HIV infection.

Of our last five cases of male rape reported to the police, only one resulted in a conviction. The assailant was convicted of buggery and was given a derisory sentence of three months' imprisonmen suspended for 15 months. A sentence of this kind shows the failure of English law to acknowledge the seriousness of these assaults and does nothing to encourage other victims to report such crimes.

HELEN LACEY RAINE ROBERT

St Mary's Sexual Assault Referral Centre, Manchester M13

P D WOOLEY $S$ CHANDIOK

\section{Withington Hospital,}

Manchester M20 8LR

1 King MB. Male rape. BMf 1990;301:1345. (15 December.)

2 Kaufman A, Divasto P, Jackson R, Christy J. Male rape victim noninstitutionalized assault. Am $\mathcal{F}$ Psychiatry 1980;137:221-3. 3 Lacey H. Sexually transmitted diseases and rape: the experience of-a sexual assault centre. International fournal of Sexually of- a sexual assault centre. International form
Transmitted Diseases and AIDS 1990;1:405-9.

SIR, - To Dr Michael B King's list of those who are at risk from male rape ${ }^{1}$ can be added the male to female transsexual. Even after medical and surgica treatment leading to reassignment in the female gender a transsexual remains male according to the law and cannot, therefore, be raped.

As after surgery the external genitalia of the transsexual are identical with those of a naturally born woman this anomaly is absurd and unjust. A victim will also not be offered anonymity and may well decide not to report an attack to avoid unpleasant publicity. The law should be changed so that reassigned transsexuals are recognised as women. Moreover, reassigned transsexuals who offend and are sentenced to imprisonment should be admitted to a prison catering for their presen gender. Regrettably, wrong placements are still made.

Wedhampton,

Devizes SN10 3PZ

1 King MB. Male rape. BMF 1990;301:1345. (15 December.)

SIR, - We wholeheartedly support Dr Michael B King's timely and apposite editorial concerning the ill understood and infrequently reported even of male rape, ${ }^{\prime}$ but our approach to the problems associated with the management of male victims of sexual assault differs in one important way from that suggested by his article.

The threat of contracting HIV as a consequence of assault is often used by the assailant as a means of gaining power over the victim. ${ }^{2}$ This may exacerbate the victim's feeling of uncleanliness and his psychological difficulties in coming to term with the attack. A policy of mandatory HIV testing after sexual assault, as suggested by Dr King, would, we believe, reinforce this attitude and discourage victims from coming forward for medical assessment after an attack.

Our current practice ${ }^{3}$ is to offer HIV testing after the victim has had time to deal with the psychological trauma consequent on the attack and after counselling. In such situations we suggest storing serum obtained at initial presentation for testing at a later date if requested.

R J HILLMAN D R TOMLINSON J R W HARRIS

Academic Department of Genitourinary Medicine,

St Mary's Hospital,

London W2 INY

I King MB. Male rape. BMF 1990;301:1345-6. (15 December.)

Hillman RJ, O'Mara N, Taylor-Robinson D, Harris JRW.

Medical and social aspects of sexual assault of males: a survey of 100 victims. Br f Gen Pract 1990;40:502-4.

3 Hillman RJ, Tomlinson D, McMillan A, French PD, Harris JRW. Sexual assault of men: a series. Genitourin Med 1990;66:247-50.

\section{Recording diastolic blood pressure in pregnancy}

SIR, - We agree with Dr I J Perry and colleagues that their findings must be replicated before phase $\mathrm{V}$ diastolic pressure is accepted for obstetric practice $^{1}$ as there are several deficiencies in their arguments. They do not state, for example, the gestation at which the blood pressures were recorded, the parity and obstetric history of the women, or their smoking habits, all of which might have an influence on diastolic pressure and the difference between phases IV and V. They do not state the number in which there was a zero value for phase V. In $5 \%$ of their cases there was a difference greater than $10 \mathrm{~mm} \mathrm{Hg}$ between phases IV and $V$ and in $20 \%$ a difference greater than $5 \mathrm{~mm} \mathrm{Hg}$. Previous workers found the data provided by the phase $\mathrm{V}$ end point unsuitable for statistical analysis because of the large number of very low and zero values. ${ }^{2}$ Also the variation between visits for each patient was much larger for phase $\mathrm{V}$ than phase IV, and this would outweigh the fact that the interobserver error is less with phase $\mathrm{V}$ than with phase IV.

As the diagnosis of gestational hypertension of the World Health Organisation and the International Society for the Study of Hypertension in Pregnancy is based on phase $I^{34}$ the use of phase $\mathrm{V}$ would mean an unnecessary increase in the numbers of women diagnosed as hypertensive. Before using phase $\mathrm{V}$ it would need to be shown to be better than phase IV at predicting a poor outcome of pregnancy. Meanwhile, phase IV should be retained for the diastolic pressure in obstetric practice, and all who undertake antenatal care should be trained adequately in its use.

IAN MACGILLIVRAY PETER THOMA

Institute of Child Health,

Royal Hospital for Sick Children,

Bristol BS2 8BJ

1 Perry IJ, Stewart BA, Brockwell J, et al. Recording diastolic blood pressure in pregnancy. $B M \mathcal{J} 1990 ; 301: 1198$. (24 November.)

2 MacGillivray I, Rose GA, Rowe B. Blood pressure survey in pregnancy. Clin Sci 1969;37:395-407.

3 World Health Organisation. The hypertensive disorders of pregnancy. WHO Tech Rep Ser 1987; No 758.
prealth Organisation. The hypertensive

pregnancy. WHO Tech Rep Ser 1987; No 758 . Davey DA, MacGillivray I. The classification and definition of the hypertensive disorders of pregnancy. Am $\mathcal{J}$ Obstet Gynecol
$198 ; 158: 892-8$.

AUTHORS' REPLY,-We welcome the opportunity to present additional data. The median gestation of the pregnant group was 34 (interquartile range 31-38) weeks; 49 of the 197 women were primiparous, 42 were para 1, 82 were para 2 or greater, and in 24 data on parity were not recorded. 
We are aware of the association of smoking with an increased difference between phase IV and V diastolic pressure. ${ }^{1}$ In our study there was an unusually high proportion of smokers in the pregnant group (23\%) compared with $10 \%$ in the control group, recruited principally from hospital staff. Accordingly, when smokers were excluded from the analysis the difference between phase IV and $\mathrm{V}$ diastolic pressure in the pregnant group (median $2.6 \mathrm{~mm} \mathrm{Hg}$, interquartile range 0.0 to 4.6 ) was even less than that reported in our paper (median $2.7 \mathrm{~mm} \mathrm{Hg}$, interquartile range 0.7 to 4.7 ) and was closer to that observed in the nonpregnant group. No pregnant woman in our sample had a zero value for phase $\mathrm{V}$ diastolic pressure. The widest difference between phases IV and $\mathrm{V}$ was $22 \mathrm{~mm} \mathrm{Hg}$.

We are familiar with the work of MacGillivray and colleagues, who described a large number of very low and zero phase $\mathrm{V}$ values in pregnancy. This has not been our experience in our obstetric hypertension clinic, and our study was therefore designed specifically to examine this issue. Given that interobserver error is less with phase $\mathrm{V}$ than with phase IV, the greater variation between visits for phase $\mathrm{V}$ may in fact be a more accurate reflection of the true physiological variation in diastolic blood pressure over the course of pregnancy.

A larger difference between phase IV and $\mathrm{V}$ diastolic pressure was associated in our data with lower systolic and lower phase IV diastolic pressure. This suggests that the adoption of phase $\mathrm{V}$ diastolic pressure would not be associated with a substantial change in the numbers currently diagnosed as hypertensive. Indeed in MacGillivray and colleagues' study only four of 226 primagravidas had phase IV diastolic pressure above 90 $\mathrm{mm} \mathrm{Hg}$ and phase $\mathrm{V}$ below $90 \mathrm{~mm} \mathrm{Hg}$. The recommendation that we use different diastolic end points in pregnant and non-pregnant women is a source of confusion. ${ }^{3}$ Automated blood pressure monitors that record phase $\mathrm{V}$ pressure are now widely used in pregnancy. We suggest that those who would retain phase IV diastolic pressure need to provide evidence that it is superior to phase $\mathrm{V}$ in predicting the outcome of pregnancy.

IVAN PERRY D G BEEVERS D M LUESLEY

University Departments of Medicine and Obstetrics Dudley Road Hospital, Birmingham B18 7QH

1 Hense H-W, Stieber J, Chambless L. Factors associated with measured differences between fourth and fifth phase diastolic blood pressure. Int $\mathcal{F}$ Epidemiol 1986;15:513-8.

2 MacGillivray I, Rose GA, Rowe B. Blood pressure survey in pregnancy. Clin Sci 1969;37:395-407.

3 Perry IJ, Wilkinson LS, Shinton RA, Beevers DG. Conflictin views on the measurement of blood pressure in pregnancy. $\mathrm{Br} \mathcal{F}$ Obstet Gynaecol (in press).

\section{Too many ethical committees}

SIR, - Dr Tamzin J Berry and colleagues argue that there are too many ethical committees and press for a national coordinating committee with only one research ethics committee in each district, which could opt out of nationally approved research.' Their argument is less than convincing, given their analysis. They are quite correct to point out the administrative chaos at present. Others have done so recently in the $B M F .^{2} \mathrm{I}$ am currently looking at 25 local research ethics committees in the United Kingdom and conducting a brief survey of the membership of as many others as possible. I too have found that the Royal College of Physicians' list of names and addresses was inaccurate and that there are a number of districts with more than one research ethics committee. There are also further complications in those research ethics committees that are shared between universities and district health authorities, making indemnity arrangements a nightmare, and some committees which rarely meet. But the answer to these administrative headaches is to get the organisation right and for health authorities to pay for a proper administrator. Those that have an enthusiastic and knowledgeable administrator, for whom it is a recognised major part of the work, function a great deal better than those that rely on the activities of the secretary or chairman of the committee with little or no secretarial back up.

The truth of the matter is that research ethical committees are still not taken seriously in many district health authorities and that a national coordinating committee might well make that worse, in that local activity would be given even lower priority. There are other, much more convincing reasons for a national coordinating committee, but they do not lie in the administrative chaos of local committees, and the principle of a local committee, sensitive to a local community, meeting to vet research protocols is not something to lose lightly.

The Department of Health is finally to issue new guidelines for research ethics committees in the very near future, after its draft guidelines published in $1989^{3}$ and following the Royal College of Physicians' excellent guidelines published in early

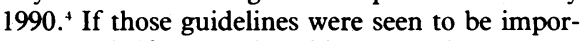
tant, and if research ethics committees were monitored and district health authorities expected to pay for adequate secretarial support, we might see a very different picture.

JULIA NEUBERGER

King's Fund Institute

London NW1 7NF

1 Berry TJ, Ades TE, Peckham CS. Too many ethical committees. BMf 1990;301:1274. (1 December.)

2 Gilbert C, Fulford KWM, Parker C. Diversity in the practice of district ethics committees. BMF 1989;299:1437-9.

3 Department of Health. DoH guidelines for local research ethics committees. London: $\mathrm{DoH}, 1989$

4 Royal College of Physicians. Guidelines on the practice of ethics committees in medical research involving human subjects. London: RCP, 1990.

SIR,-Ms Tamzin J Berry and colleagues report many administrative problems but ethical problems in only two of the 43 districts where they undertook research on AIDS and recommend clear cut guidelines for ethical committees that review multicentre research applications. ${ }^{1}$ Our experience, however, suggests a need for wider debate on the role of ethical committees.

Our study, evaluating the Health Education Authority's 1989 initiative to raise students' awareness of HIV infection, ${ }^{2}$ was delayed by being twice rejected by ethical committeesonce because complete anonymity had not been assured (although the most sensitive section of the questionnaire was on a detachable sheet that could be returned separately and the key to respondents' identities would be kept in a different room from the completed questionnaires and be held by the project supervisor) and again through what we thought was concern with methodological issues as much as ethical ones. The delay prevented a proper pilot study, and guaranteeing anonymity cost an extra $£ 1030$ because of the need for extra reminders. ${ }^{3}$

Is complete anonymity essential when respondents give informed consent by completing questionnaires and when sensitive questions can be returned anonymously? Other surveys have used the "detachable self completion" technique for sensitive topics. ${ }^{45}$ Must ethical committees see definitive questionnaires before giving approval, or just a checklist of topics to be studied? Questionnaires need to be tested with pilot studies before they are definitive, and such studies may be unethical in the absence of ethical approval. Designing questionnaires is a painstaking and time consuming activity, and researchers are often reluctant to devote the required attention to it until ethical approval has been granted. Should it be the concern of ethical committees to comment on study objectives and on the design, reliability, and validity of questionnaires-moreover, do they have the necessary expertise? Should ethical studies be given ethical approval to proceed with further planning? Such approval may be essential for evaluation research, in which delays can jeopardise the proposed study.

A fresh look at the role of ethical committees in survey research is needed, particularly in HIV infection and AIDS. We support those who plead for less bureaucracy, and propose that ethical committees should consider ethical issues such as consent, confidentiality, and the human costs versus the likely benefits of research. 'On scientific matters their advice is welcome, but its acceptance should not be a condition of ethical approval.

RAJAN MADHOK ROBERT T MCEWAN RAJ S BHOPAL ALISON MCCALLUM

Division of Epidemiology and Public Health,

Medical School,

University of Newcastle upon Tyne,

Newcastle upon Tyne NE2 4HH

1 Berry TJ, Ades TE, Peckham C. Too many ethical committees. BMF 1990;301:1274. (1 December.)

2 Bhopal RS, Madhok R, McCallum A, McEwan RT. An evaluation of the HEA's student HIVIAIDS initiative (1989). Newcastle of the HEA's student HIVIAIDS initiative (1989). Newcastle
upon Tyne: Division of Epidemiology and Public Health, upon Tyne: Division of Epidemiology

3 Madhok R, McEwan RT, Bhopal RS, McCallum A. Anonymous postal surveys. F Epidemiol Community Health 1990;44:253.

4 Johnson AM, Wadsworth J, Elliot $P$, et al. A pilot study of sexual lifestyle in a random sample of the population of Great Britain. AIDS 1989;3:135-41.

5 Bowie C, Ford N. Sexual behaviour of young people and the risk of HIV infection. I E pidemiol Community Health 1989;43:61-5.

SIR,-All the problems that Dr Tamzin J Berry and colleagues experienced in obtaining approval from district ethical committees for their study ${ }^{1}$ can, in our experience of multicentre trials, be overcome by the local district coordinator of the multicentre study taking the protocol to his or her district ethical committee. We would therefore oppose the idea that approval should be given at national level with the local districts being able to opt out, because this would result in loss of local input to such studies, would not allow for local variations, and would reduce the chances that any problems with the study might be detected.

M D M SHAW P R D HUMPHREY

Mersey Regional Department of Medical

and Surgical Neurology,

Walton Hospital,

Liverpool L9 1AE

Berry TJ, Eades TE, Peckham C. Too many ethical committees. $B M \mathcal{F}$ 1990;301:1274. (1 December.)

\section{Kwashiorkor}

SIR, - It is Dr Tony Waterston, ${ }^{1}$ not Professor P D Marsden, ${ }^{2}$ who has got it wrong about the aetiology of kwashiorkor. That the disease occurs because of protein energy malnutrition is an indisputable clinicoepidemiological fact that only laboratory based researchers have hitherto dared to question.

The word kwashiorkor (kwasiokor in Krobo, where there is no "sh" in the alphabet) is from the Ga-Krobo-Adangbe megatribe of south eastern Ghana, to which I belong. The word does not mean red hair as textbooks have guessed wrongly over the years. It is, primarily, a sibling positional word, which requires careful explanation to the non-native. It was said of me (the second child) the day my younger brother was born while I was not yet completely weaned: "afor ese kwasiorkor" which, literally, is "it has been born after him kwasiorkor." I was expected to develop kwashiorkor because of the birth of my brother. The reason 